\title{
Up-regulation of TGF- $\beta$ via the activation of extracellular signal-regulated kinase 1 and 2 induced by prorenin in human renal mesangial cells
}

\author{
WEI SONG*, YING ZHANG ${ }^{*}$, CHEN JIA, LILI REN, YUMEI MI, YAN LU and YINONG JIANG
}

\author{
Department of Cardiology, The First Affiliated Hospital of Dalian Medical University, Dalian, Liaoning 116011, P.R. China
}

Received March 12, 2011; Accepted September 23, 2011

DOI: $10.3892 / \mathrm{mmr} .2011 .615$

\begin{abstract}
Prorenin is thought to be an inactive precursor of renin. This study investigated whether human prorenin was capable of activating the (pro)renin receptors $[(\mathrm{P})$ RRs], leading to the phosphorylation of extracellular signalregulated kinase 1 and 2 (ERK1/2) in cultured human renal mesangial cells (HRMCs). HRMCs cultured in vitro were pretreated with an $\mathrm{AT}_{1}$ and $\mathrm{AT}_{2}$ blocker prior to stimulation by prorenin, PD98059 (an inhibitor of ERK1/2) and handleregion peptide (HRP). Phosphorylated ERK1/2 was evaluated using Western blot analysis, and the concentration of TGF- $\beta$ was measured by ELISA. The mRNA of TGF- $\beta$ was evaluated by RT-PCR. It was found that prorenin activated the $(\mathrm{P})$ RR in cultured HRMCs, which in turn increased p-ERK1/2. Prorenin induced rapid phosphorylation of ERK1/2 and increased p-ERK1/2 in a time- and dose-dependent manner. The protein levels of TGF- $\beta$ increased significantly with the stimulation of prorenin. PD98059 significantly decreased p-ERK1/2 and then downregulated TGF- $\beta$. HRP did not inhibit either ERK1/2 phosphorylation or the increase in TGF- $\beta$. ERK1/2 phosphorylation induced by prorenin led to a marked increase in TGF- $\beta$. The regulation of TGF- $\beta$ was highly dependent on ERK1/2. Thus, ERK1/2 may play a key role in the development of kidney disease. HRP neither affects the ERK1/2 signaling nor the level of TGF- $\beta$ in HRMCs.
\end{abstract}

\section{Introduction}

It is traditionally thought that the biologically active peptide angiotensin II plays a key role in the development of diseases

Correspondence to: Dr Yinong Jiang, Department of Cardiology, The First Affiliated Hospital of Dalian Medical University, Dalian, Liaoning 116011, P.R. China

E-mail: jiangyn64510@yahoo.com.cn

*Contributed equally

Key words: prorenin, prorenin receptor, ERK1/2 signal transduction, handle-region peptide, human renal mesangial cells associated with renin-angiotensin system (RAS) activation. This hypothesis was supported by Nguyen et al (1), who first reported (pro)renin receptors [(P)RRs] in 2002. Two (P)RRs have been identified thus far. The first, the mannose-6-phosphate (M6P) receptor, is a clearance receptor. Studies showed that it binds and internalizes renin and prorenin (2). Such binding, however, does not result in intracellular angiotensin generation, and it has been concluded that the M6P/IGF2R is a clearance receptor for prorenin (3). The specific (P)RR is a 350 -amino acid protein with a single transmembrane domain that binds renin and prorenin equally well $(4,5)$. It is highly conserved across species and has no homology with other known proteins (6). Nguyen et al first detected the (P)RR in renal mesangial cells and in vascular smooth muscle cells of the coronary and renal arteries using an immunofluorescence method (1). The (P)RR is highly expressed in cardiovascular, kidney, brain and placenta tissue (7). (P)RR activation activates certain signal transduction pathways and upregulates the expression of certain genes as well as enhancing the enzymatic activity of prorenin (8). (P)RR has become the focus of much research since it was recognized as being associated with diseases involving RAS activation.

Suzuki et al developed a decoy peptide according to the epitope of the prorenin prosegment, which was termed the handle-region peptide (HRP) (9). The HRP ostensibly blocks the binding of prorenin to the (P)RR, but there is no adequate evidence to support the hypothesis that the HRP is the blocker of the (P)RR. In this study, we aimed to demonstrate whether the HRP inhibits (P)RR in HRMCs.

The (P)RR is highly conserved across species (10). Several studies carried out on genetic model animals have shown that the $(\mathrm{P}) \mathrm{RR}$ plays a pivotal role in the processes of myocardial fibrosis and glomerular sclerosis (11-14). However, no evidence of the (P)RR pathological mechanism in humans exists. Proliferation of human renal mesangial cells HRMCs is a common indicator of hypertension nephropathy and diabetic nephropathy. The proliferation of HRMCs and the cytokines produced by them play key roles in hypertensive nephropathy and diabetic nephropathy. The purpose of this study was to investigate the effect of the (P)RR on the activation of ERK1/2 and the fibrotic factor TGF- $\beta$ on HRMCs. Furthermore, the study aimed to evaluate whether the putative (P)RR blocker HRP inhibits this pathway in HRMCs. 


\section{Materials and methods}

Cell culture. The HRMCs and modified Eagle's medium (MEM) were purchased from ScienCell Research Laboratories (San Diego, CA, USA). The cells were incubated in MEM supplemented with $10 \%$ bovine calf serum (BCS) in a humidified atmosphere of $95 \%$ air plus $5 \% \mathrm{CO}_{2}$. When the cells reached approximately $80 \%$ confluence, they were digested by $0.025 \%$ trypsinase at $37^{\circ} \mathrm{C}$ for $2 \mathrm{~min}$. Medium that contained $10 \%$ fetal bovine serum was used to terminate the reaction. The third to fifth generations were used to carry out the study, and the cells were cultured in serum-deprived medium for $24 \mathrm{~h}$ prior to the experiment.

Reverse transcription-polymerase chain reaction (RT-PCR) to detect the TGF- $\beta$ mRNA. Total RNA was extracted from HRMCs using TRIzol reagent (Invitrogen, Carlsbad, CA, USA). The total RNA was solubilized in RNase-free water and quantified by measuring the optical density (OD) at $260 \mathrm{~nm}$. The RNA purity was determined by obtaining a $260 / 280 \mathrm{~nm}$ OD ratio of $>1.70$. A sample of total RNA $(2 \mu \mathrm{g})$ was reverse transcribed into cDNA in a $20 \mu 1$ reaction mixture. Primers for TGF- $\beta$ (forward, 5'-GCATGGAGTOCTGTGGCAT-3'; reverse, 5'-CTAGAAGCATTTGCGGTGG-3') and $\beta$-actin (forward, 5'-CCGCAAGGACCTCGGCTGGAA-3'; reverse, 5'-GATCATGTTGGACAGCGCTC-3') were designed based on previously reported cDNA sequences. A primer designer (Primer Premier 5.0 software) was used to design primers for TGF- $\beta$. The primers were synthesized by Takara, Japan. The $25 \mu \mathrm{l}$ PCR solution contained $1.5 \mathrm{mM} \mathrm{MgCl} 2,0.2 \mathrm{mM}$ deoxynucleotide triphosphates and 1 unit of Taq DNA polymerase (Gibco-BLR, Gaithersburg, MD, USA). The PCR program was as follows: $94^{\circ} \mathrm{C}$ for 2 min for the initial step; $94^{\circ} \mathrm{C}$ for $45 \mathrm{sec}, 58^{\circ} \mathrm{C}$ for $45 \mathrm{sec}$ and $72^{\circ} \mathrm{C}$ for $1 \mathrm{~min}$ for 20 cycles; and a final extension at $72^{\circ} \mathrm{C}$ for $10 \mathrm{~min}$. Following amplification, the reaction products were electrophoresed on $1 \%$ agarose TAE gels and then EB-stained. TGF- $\beta$ mRNA was normalized with the housekeeping gene $\beta$-actin mRNA and was analyzed using the UVP Bioimaging System (LabWorks ${ }^{\mathrm{TM}}$, Version 4.6, USA).

Western blot analysis of ERK1/2. Western blot analyses were performed as previously reported. Briefly, the cultured HRMCs were lysed in lysis buffer containing Tris $(50 \mathrm{mM}), \mathrm{NaCl}(100 \mathrm{mM}), \mathrm{NAF}(50 \mathrm{mM})$, EDTA $(1 \mathrm{mM})$, $0.1 \%$ sodium dodecyl sulfate (SDS), $0.5 \%$ deoxycholic acid sodium salt, $1 \%$ Triton X-100 and protease inhibitor (1 $\mathrm{tab} / 9 \mathrm{ml}$ buffer). Following centrifugation at $15,000 \mathrm{rpm}$ for $15 \mathrm{~min}$ at $4^{\circ} \mathrm{C}$, the supernatant was collected and subjected to SDS polyacrylamide gel electrophoresis. The proteins were transferred to polyvinylidene difluoride membranes. After blocking the blots for $3 \mathrm{~h}$ at room temperature with TBS-T containing 5\% bovine serum albumin and $0.5 \%$ Tween-20, they were incubated for $24 \mathrm{~h}$ with rabbit monoclonal anti-phosphorylated ERK antibody (1:200 dilutions, Santa Cruz Biotechnology, Japan). Immunoreactivity was detected by horseradish-peroxidase-conjugated goat antirabbit secondary antibody. Protein bands were detected with an ECL detection kit (Pierce, Rockford, IL, USA) and recorded on X-ray film. The band densities were quantified by a LabWorks system. The change in ERK1/2 phosphorylation was reflected by the relative abundance of p-ERK $1 / 2$ to that of ERK1/2.

Statistical analysis. Standard statistical methods from the SPSS Statistical Analysis System V-16.0 (SPSS, Chicago, IL, USA) were used. Statistical comparisons were made by using a two-way ANOVA test. Values of $\mathrm{P}<0.05$ were considered to indicate statistical significance. The data are reported as the means \pm SEM. Duplicate wells were analyzed for each experiment, and each experiment was performed independently at least three times.

\section{Results}

The impact of various concentrations of prorenin on phosphorylated ERK1/2. To investigate the impact of various concentrations of prorenin respectively on the activation of ERK1/2, the cells were treated with $5 \times 10^{-9}, 5 \times 10^{-10}, 5 \times 10^{-11}$, $5 \times 10^{-12}$ or $5 \times 10^{-13} \mathrm{M}$ prorenin. It was found that phosphorylation of ERK1/2 is concentration-dependent. p-ERK1/2 increased at $5 \times 10^{-10} \mathrm{M}$ and markedly increased at $5 \times 10^{-9} \mathrm{M}$. Thus, $5 \times 10^{-9} \mathrm{M}$ prorenin was used in the subsequent experiments (Fig. 1).

Effect of prorenin on ERK1/2 activation induced by $(P) R R$ at various time points. Cells were harvested at $0,2.5,5,10$, 20,35 or 60 min following the administration of prorenin at $5 \times 10^{-9}$ M. p-ERK was measured using the Western blot method. No difference was found between 0 and $2.5 \mathrm{~min}$, and although p-ERK increased 5 min after the addition of prorenin, there was no disparity after $20 \mathrm{~min}$ of stimulation. Therefore, human recombinant prorenin induced long-lasting phosphorylation of ERK1/2 by activating (P)RR in cultured HRMCs (Fig. 2).

Effects of HRP and PD98059 on ERK1/2 activation induced by human recombinant prorenin in HRMCs. To evaluate whether HRP and prorenin induced the phosphorylation of ERK1/2 in cultured HRMCs, angiotensin II type 1 and 2 receptors were blocked using olmesartan and PD123319, respectively, at $5 \times 10^{-5} \mathrm{M}$. The same concentration of prorenin was used as mentioned previously. PD98059 (an inhibitor of ERK1/2) was used to inhibit the phosphorylation of ERK1/2, and $10 \mu \mathrm{M}$ HRP was added. The cells were harvested following a $35 \mathrm{~min}$ incubation. The protein levels of p-ERK increased, in addition to the activation of (P)RR induced by prorenin. PD98059 inhibited the increase of p-ERK1/2, but the HRP did not have the same effect (Fig. 3).

Effects of the HRP and PD98059 on TGF- $\beta$ secretion induced by human recombinant prorenin in HRMCs. To demonstrate the role of prorenin and HRP on the levels of TGF- $\beta$, the protein concentration of TGF- $\beta$ in the medium of cultured cells was measured using ELISA following stimulation with these factors. The bar chart shows that TGF- $\beta$ markedly increased compared with the control when treated with prorenin. PD98059 was not markedly different from the control. The HRP again failed to reduce the protein levels of TGF- $\beta$ induced by the (P)RR (Fig. 4). 

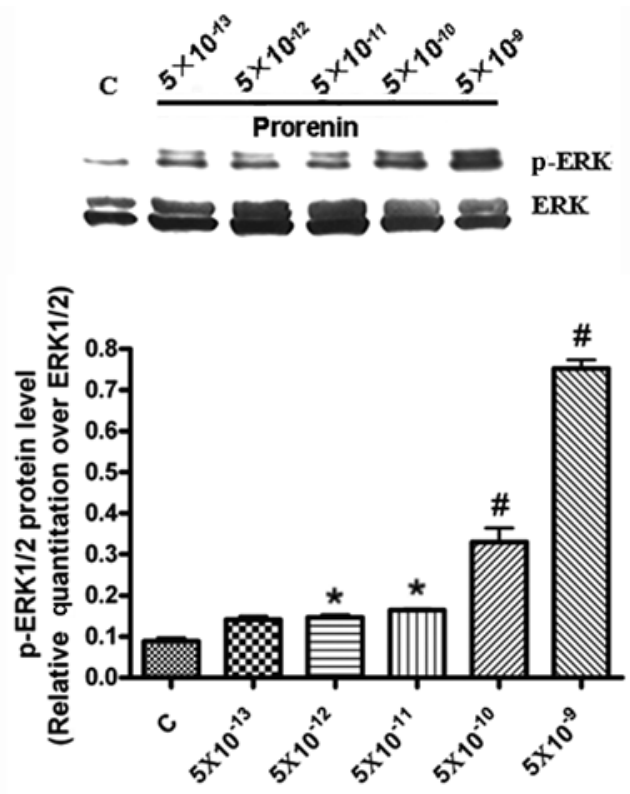

Prorenin concentration (mol/l)

Figure 1 . The activation of p-ERK1/2 following stimulation by prorenin at various concentrations. The bar chart shows the relative density of phosphorylated p-ERK1/2 to ERK1/2. ${ }^{*} \mathrm{P}<0.05$ vs. control, ${ }^{\#} \mathrm{P}<0.01$ vs. control (C, control; $\mathrm{n}=3$ ).
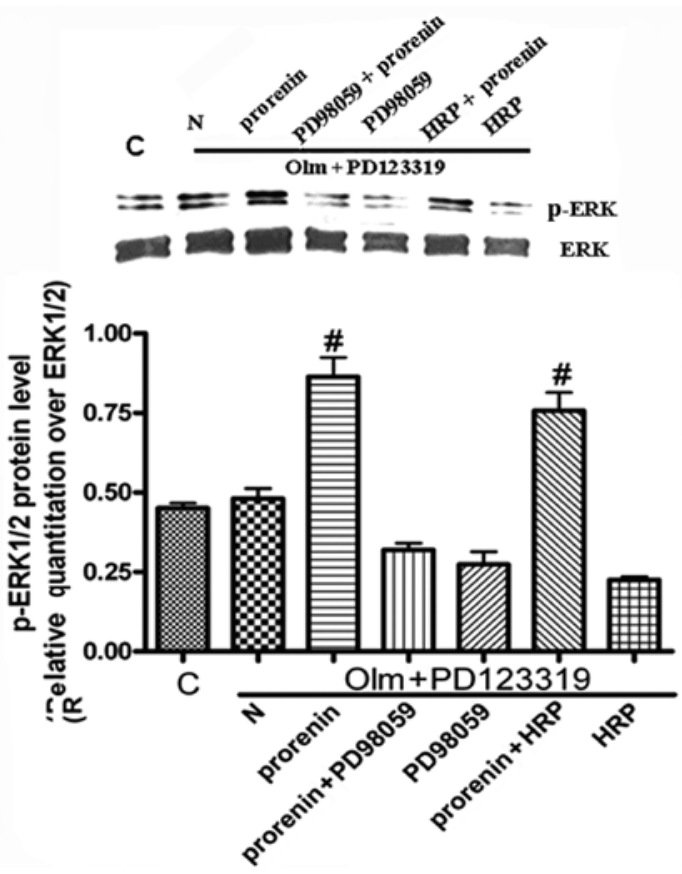

Figure 3. The effect of prorenin, HRP and the inhibitor of ERK1/2 on p-ERK1/2 in HRMCs. HRMCs were pretreated with the AT1 blocker olmesartan (olm) and the AT2 blocker PD123319 at $5 \times 10^{-5} \mathrm{~mol} / 1$ and then co-incubated with other reagents. A Western blot analysis was performed. The graph shows the relative levels of p-ERK1/2 compared with ERK1/2 in each group ( $\mathrm{C}$, control; $\mathrm{N}$, no additive; $\mathrm{n}=2$; $\left.{ }^{"} \mathrm{P}<0.01\right)$.

Effects of the HRP and PD98059 on TGF- $\beta$ mRNA induced by human recombinant prorenin in HRMCs. To study whether prorenin and the HRP affect the TGF- $\beta$ mRNA levels, the mRNA of TGF- $\beta$ in the harvested cultured cells
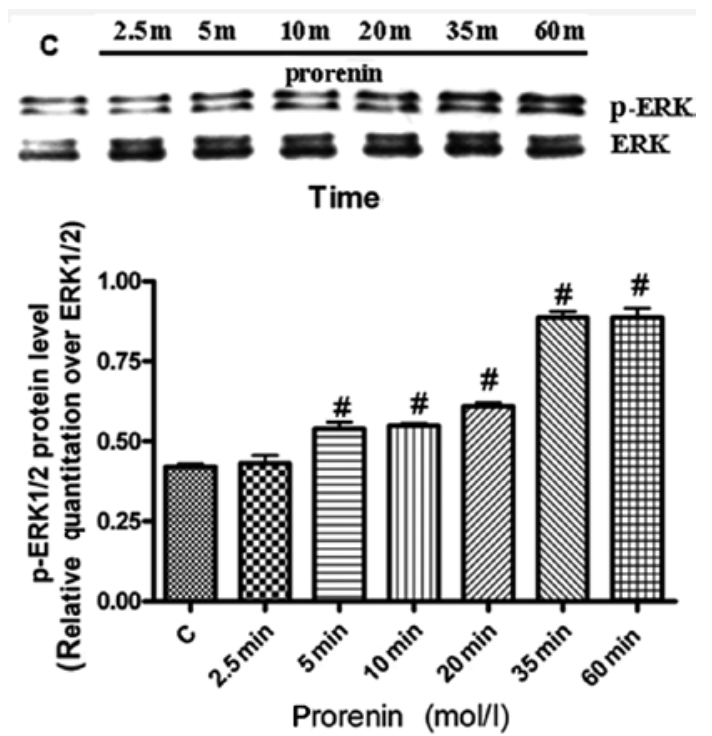

Figure 2. The time course of p-ERK1/2 following the addition of human prorenin at $5 \times 10^{-9} \mathrm{M}$ to HRMCs. Western blot analyses were carried out. The bar chart of the band shows the density of phosphorylated p-ERK1/2 to ERK1/2 bands. ${ }^{~} \mathrm{P}<0.01$ vs. control ( $\mathrm{m}, \mathrm{min} ; \mathrm{C}$, control, $\mathrm{n}=3$ ).

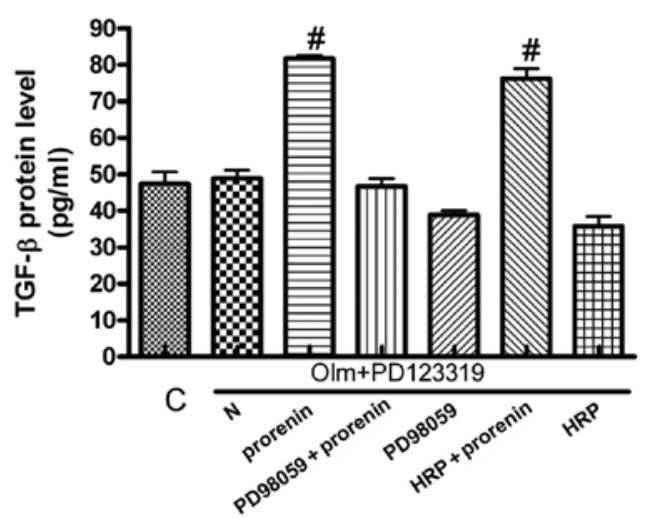

Figure 4. The effects of prorenin, HRP and inhibitor of ERK1/2 on TGF- $\beta$ production in HRMCs. HRMCs were pretreated as mentioned previously. The graph shows the relative levels of TGF- $\beta$ evaluated by ELISA in each group. The value is expressed relative to no additive $(\mathrm{N})$ and control (C). ${ }^{\#} \mathrm{P}<0.01$ compared with the control $(\mathrm{n}=4)$.

was measured with the RT-PCR method following stimulation with prorenin and HRP. We found that the TGF- $\beta$ mRNA levels markedly increased when compared with the control. PD98059, but not HRP, inhibited the TGF- $\beta$ mRNA expression induced by the (P)RR. The protein level of TGF- $\beta$ was consistent with its mRNA level. This result indicates that the regulation of TGF- $\beta$ is highly dependent on ERK1/2 signaling transduction (Fig. 5).

\section{Discussion}

Target-organ protection from hypertension is a controversial issue in clinical research. Studies have shown that the early stage of hypertensive nephropathy includes glomerular hypertrophy and cell proliferation; however, most of the proliferative cells are renal mesangial cells. HRMCs cultured 

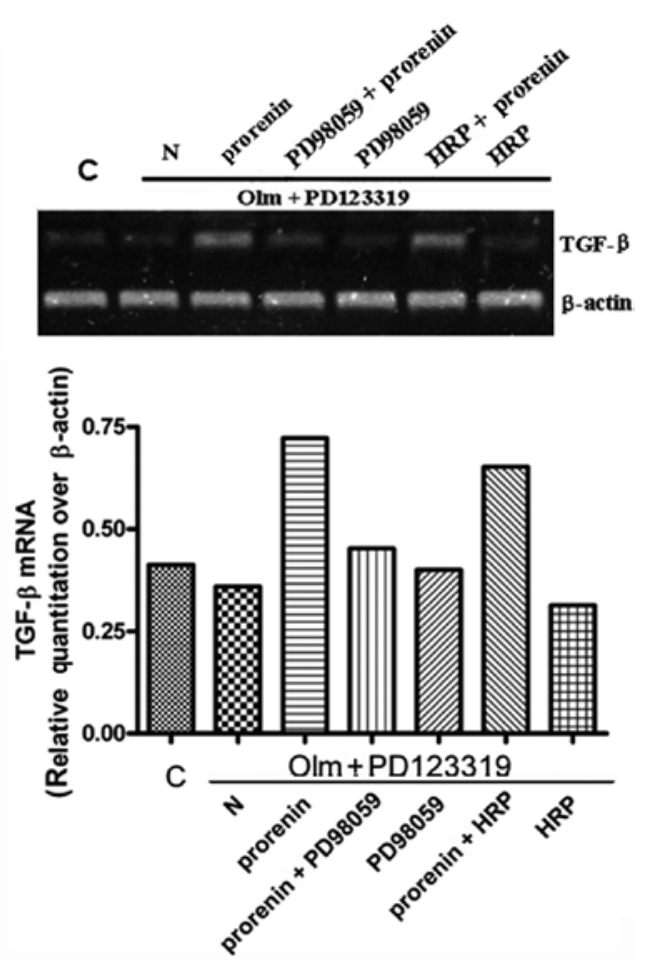

Figure 5. The effects of prorenin, HRP and the inhibitor of ERK1/2 on TGF- $\beta$ mRNA expression in HRMCs. HRMCs were pretreated. RT-PCR was performed. The graph shows the relative levels of TGF- $\beta$ mRNA compared with $\beta$-actin in each group $(n=1)$.

in vitro were treated with various concentrations of human recombinant prorenin. The results demonstrated that prorenin rapidly induced ERK1/2 phosphorylation of MAPKs in a dose-dependent manner. p-ERK1/2 was measured at various time points after the administration of prorenin; the p-ERK increased $5 \mathrm{~min}$ following the addition of prorenin. No disparity occured after $20 \mathrm{~min}$. A previous study reported that phosphorylation of ERK1/2 may be involved in the development of nephropathy (15). Therefore, the study shows that the mechanism through which the $(\mathrm{P}) \mathrm{RR}$ induced the rapid phosphorylation of ERK1/2 is involved in the development of nephropathy.

There are two pathways for the phosphorylation of ERK1/2 induced by prorenin. First, it is well known that prorenin-renin conversion occurs in the kidney (16). Prorenin, following its local conversion to renin, contributes to angiotensin (Ang) generation. ERK1/2 is activated when angiotensin II binds to its type 1 receptor. Second, ERK1/2 activation by $(\mathrm{P}) \mathrm{RR}$ is independent of angiotensin II generation $(8,17,18)$. To evaluate the function of (P)RR, angiotensin II type 1 and 2 receptors were blocked with olmesartan and PD123319. The cells were then incubated with prorenin. The results demonstrated that p-ERK1/2 markedly increased from the stimulation of prorenin and decreased sharply when co-incubated with the ERK1/2 inhibitor PD98059. Since $\mathrm{AT}_{1}$ and $\mathrm{AT}_{2}$ were blocked, it appears that the phosphorylation of ERK1/2 was due to (P) RR activation induced by prorenin.

The TGF- $\beta$ level was observed and it was found that prorenin increased TGF- $\beta$ mRNA levels and the secretion of TGF- $\beta$ in HRMCs. PD98059, which is an inhibitor of ERK1/2, reduced the phosphorylation of ERK1/2 and the level of TGF- $\beta$. RT-PCR and ELISA were used to test the mRNA and protein level of TGF- $\beta$, respectively; both revealed the same results. It was concluded that the regulation of TGF- $\beta$ is highly dependent on ERK1/2 signaling transduction. TGF- $\beta$ is the key mediator of renal tissue fibrosis (15). It enhances extracellular matrix synthesis and extracellular disposition, promoting mesangial cell proliferation (19). These processes play a significant role in diabetic nephropathy and kidney complications in hypertension. These results suggest a novel mechanism for the development of renal fibrosis in the presence of a high prorenin concentration, including in diabetic nephropathy. The MAPK cascade plays a pivotal role in the induction of cell differentiation, proliferation and cell stress by $\mathrm{G}$ protein-coupled receptors in response to extracellular stimulation (20). Once activated, ERK1/2 translocates to the nucleus, where it is thought to regulate the expression of transcription factors and thereby regulate cell differentiation and proliferation (21). Inhibiting ERK1/2 phosphorylation may shed light on therapies for renal disease.

In the present study, it was found that prorenin activated (P)RR, which led to the activation of ERK1/2 and increased TGF- $\beta$ in cultured HRMCs. According to a previous study, (P)RR is involved in cardiac fibrosis (22), nephrosclerosis (14) and microvascular complications (23). As a result, it was concluded that the activation of (P)RR induced by prorenin in HRMCs may be involved in the development of human renal disease. Blockers of the RAS are widely used for the treatment of cardiovascular and renal diseases. It is generally assumed that the beneficial effects of these drugs are due, at least in part, to the blockade of the generation or action of angiotensin II at the tissue site (24). This effect of the (P)RR is prevented by the angiotensin-converting enzyme (ACE) inhibitors, angiotensin II type 1 receptor blockers and aliskiren, which is a direct renin inhibitor that was introduced in the clinical arena in 2007 (25). However, the high plasma and local tissue renin and prorenin levels induced by therapeutic $\mathrm{AT}_{1}$ receptor blockers and aliskiren could conceivably induce (P)RR signaling independent of Ang II and may contribute to vascular sclerosis and renal fibrosis, thereby limiting the effectiveness of this therapy.

Since we aimed to examine a new method of blocking the effect of (P)RR, HRP was used to block the (P)RR. It was found that the HRP inhibited neither the phosphorylation of ERK1/2 nor the increase in TGF- $\beta$ induced by prorenin. The effect of the putative blocker HRP is controversial. Ichihara et al revealed that HRP normalized renal angiotensin I and angiotensin II levels. Proteinuria was also normalized, and the glomerulosclerosis was completely inhibited in double transgenic model animals. HRP effectively reversed myocardial fibrosis and reduced the collagenase type I and III levels to almost normal values $(12-14,26)$. However, HRP failed to block p-ERK1/2 in monocytes and vascular smooth muscle cells and did not affect prorenin binding to its receptor or Ang II generation (27-29). HRP did not affect blood pressure, cardiac hypertrophy and renal damage in two-kidney, one-clip Goldblatt hypertensive rats (30). However, no solid proof is currently available that clearly establishes HRP as a (P)RR blocker. The evidence shows that HRP failed to inhibit ERK1/2 phosphorylation and TGF- $\beta$ expression in HRMCs. Additional evidence is required before the role of HRP is established. 
Experimental evidence regarding the role of prorenin and (P)RR in renal damage suggests that blocking $(\mathrm{P}) \mathrm{RR}$ is a new therapeutic target for tissue protection. As an inhibitor of ERK1/2, PD98059 raises the possibility that blocking signal transduction may lead to increased tissue protection. However, whether the benefits outweigh the drawbacks have yet to be fully determined as it is unknown whether there is cross-talk between MAPK signaling pathways.

\section{References}

1. Nguyen G, Delarue F, Burckle C, Bouzhir L, Giller T and Sraer JD: Pivotal role of the renin/prorenin receptor in angiotensin II production and cellular responses to renin. J Clin Invest 109: 1417-1427, 2002.

2. Saris JJ, Derkx FH, De Bruin RJ, et al: High-affinity prorenin binding to cardiac man-6-P/IGF-II receptors precedes proteolytic activation to renin. Am J Physiol Heart Circ Physiol 280: H1706-H1715, 2001.

3. Van Kesteren CA, Danser AH, Derkx FH, Dekkers DH, Lamers JM, Saxena PR and Schalekamp MA: Mannose 6-phosphate receptor-mediated internalization and activation of prorenin by cardiac cells. Hypertension 30: 1389-1396, 1997.

4. Nguyen G, Burckle CA and Sraer JD: Renin/prorenin-receptor biochemistry and functional significance. Curr Hypertens Rep 6: 129-132, 2004

5. Nguyen G: Renin/prorenin receptors. Kidney Int 69: 1503-1506, 2006 .

6. Nguyen G: The (pro)renin receptor: a new kid in town. Semin Nephrol 27: 519-523, 2007.

7. Nguyen G: The (pro)renin receptor: pathophysiological roles in cardiovascular and renal pathology. Curr Opin Nephrol Hypertens 16: 129-133, 2007.

8. Inagami T and Ichihara A: Prorenin/renin receptor, signals, and therapeutic efficacy of receptor blocker in end-organ damage. Curr Hypertens Rep 9: 474-479, 2007.

9. Suzuki F, Hayakawa M, Nakagawa T, et al: Human prorenin has 'gate and handle' regions for its non-proteolytic activation. J Biol Chem 278: 22217-22222, 2003.

10. Batenburg WW and Jan Danser AH: The (pro)renin receptor: a new addition to the renin-angiotensin system? Eur J Pharmacol 585: 320-324, 2008.

11. Takahashi H, Ichihara A, Kaneshiro Y, et al: Regression of nephropathy developed in diabetes by (Pro)renin receptor blockade. J Am Soc Nephrol 18: 2054-2061, 2007.

12. Ichihara A, Suzuki F, Nakagawa T, et al: Prorenin receptor blockade inhibits development of glomerulosclerosis in diabetic angiotensin II type 1a receptor-deficient mice. J Am Soc Nephrol 17: 1950-1961, 2006.

13. Ichihara A, Kaneshiro Y and Suzuki F: Prorenin receptor blockers: effects on cardiovascular complications of diabetes and hypertension. Expert Opin Investig Drugs 15: 1137-1139, 2006.
14. Ichihara A, Kaneshiro Y, Takemitsu T, et al: Contribution of nonproteolytically activated prorenin in glomeruli to hypertensive renal damage. J Am Soc Nephrol 17: 2495-2503, 2006.

15. Huang $\mathrm{Y}$, Noble NA, Zhang J, Xu $\mathrm{C}$ and Border WA: Renin-stimulated TGF- $\beta 1$ expression is regulated by a mitogen-activated protein kinase in mesangial cells. Kidney Int 72: 45-52, 2007.

16. Danser AH: Local renin-angiotensin systems: the unanswered questions. Int J Biochem Cell Biol 35: 759-768, 2003.

17. Campbell DJ: Critical review of prorenin and (pro)renin receptor research. Hypertension 51: 1259-1264, 2008.

18. Schefe JH, Menk M, Reinemund J, et al: A novel signal transduction cascade involving direct physical interaction of the renin/prorenin receptor with the transcription factor promyelocytic zinc finger protein. Circ Res 99: 1355-1366, 2006.

19. Border WA and Noble NA: Transforming growth factor $\beta$ in tissue fibrosis. N Engl J Med 331: 1286-1292, 1994.

20. Muslin AJ: MAPK signalling in cardiovascular health and disease: molecular mechanisms and therapeutic targets. Clin Sci (Lond) 115: 203-218, 2008

21. Ichihara A, Kaneshiro Y, Takemitsu T, Sakoda M and Itoh $\mathrm{H}$ : The (pro)renin receptor and the kidney. Semin Nephrol 27: 524-528, 2007.

22. Ichihara A, Kaneshiro Y, Takemitsu T, et al: Nonproteolytic activation of prorenin contributes to development of cardiac fibrosis in genetic hypertension. Hypertension 47: 894-900, 2006.

23. Satofuka S, Ichihara A, Nagai N, et al: Role of nonproteolytically activated prorenin in pathologic, but not physiologic, retinal neovascularization. Invest Ophthalmol Vis Sci 48: 422-429, 2007.

24. Novo S, Lunetta M, Evola S and Novo G: Role of ARBs in the blood hypertension therapy and prevention of cardiovascular events. Curr Drug Targets 10: 20-25, 2009.

25. Jensen $C$, Herold $P$ and Brunner HR: Aliskiren: the first renin inhibitor for clinical treatment. Nat Rev Drug Discov 7: 399-410, 2008.

26. Ichihara A, Hayashi M, Kaneshiro Y, et al: Inhibition of diabetic nephropathy by a decoy peptide corresponding to the 'handle' region for nonproteolytic activation of prorenin. J Clin Invest 114: 1128-1135, 2004.

27. Batenburg WW, Krop M, Garrelds IM, et al: Prorenin is the endogenous agonist of the (pro)renin receptor. Binding kinetics of renin and prorenin in rat vascular smooth muscle cells overexpressing the human (pro)renin receptor. J Hypertens 25: 2441-2453, 2007

28. Feldt S, Batenburg WW, Mazak I, et al: Prorenin and renin-induced extracellular signal-regulated kinase $1 / 2$ activation in monocytes is not blocked by aliskiren or the handle-region peptide. Hypertension 51: 682-688, 2008.

29. Feldt S, Maschke U, Dechend R, Luft FC and Muller DN: The putative (pro)renin receptor blocker HRP fails to prevent (pro) renin signaling. J Am Soc Nephrol 19: 743-748, 2008.

30. Muller DN, Klanke B, Feldt S, et al: (Pro)renin receptor peptide inhibitor 'handle-region' peptide does not affect hypertensive nephrosclerosis in Goldblatt rats. Hypertension 51: 676-681, 2008. 